\title{
A formação profissional em escolas primárias e em escolas normais primárias portuguesas (1844-1926)
}

\author{
Vocational training in primary and in normal primary schools \\ in Portugal (1844-1926) \\ La formación profesional en las escuelas primarias y en las \\ escuelas normales primarias portuguesas (1844-1926) \\ José MANUEL Matos ${ }^{1}{ }^{1}$ \\ ALEXANDRA RODRIGUES ${ }^{2}{ }^{2}$ \\ RUI CANDEIAS (1) 2 \\ ${ }^{1}$ Universidade Federal de Juiz de Fora, Juiz de Fora, MG, Brasil. \\ ${ }^{2}$ UIED - Unidade de Investigação Educação e Desenvolvimento da Universidade Nova de Lisboa, Caparica, Portugal.
}

\begin{abstract}
RESUMO
Desde a reforma de 1844 que o ensino primário português passou a prever, após um $1^{\mathrm{O}}$ grau de formação genérica centrada na trilogia ler, escrever e contar, um $2^{\circ}$ grau, e, entre 1911 e 1926 , um $3^{\circ}$ grau, designado por superior, com cursos práticos especiais para o ensino agrícola, industrial, comercial ou marítimo, de acordo com a localização das escolas, e que se reconhece também como um embrião de formação. Este artigo pretende pois estudar os modos como as escolas normais primárias abordaram a formação de professores nestas áreas no período 1844-1926 e, em particular, saber como o ensino da matemática nessas escolas se adaptou a essa finalidade.
\end{abstract}

Palavras-chave: História do ensino da matemática. Ensino profissional. Ensino primário. Escolas normais. Formação de professores.

\begin{abstract}
Since the reform of 1844 , Portuguese primary education began to encompass, after the first degree of generic education centered in the trilogy to read, to write and to count, a second degree, and, between 1911 and 1926, a third degree, designated as superior, with special practical courses for agricultural, industrial, commercial or maritime education, according to the location of the schools, which is also recognized as a training embryo. This article intends to study the ways in which normal primary schools have approached training in these areas between 1844 and 1926 and, in particular, to know how the teaching of mathematics in these schools has adapted to this purpose.
\end{abstract}

Keywords: History of teaching mathematics. Professional teaching. Primary school. Normal schools. Teacher education.

\section{RESUMEN}

Desde la reforma de 1844 que la escuela primaria portuguesa ofrece, después de un 1 grado de formación genérica centrada en la trilogía lectura, escribir y contar, un segundo grado y entre 1911 y 1926 un tercer grado, que se designa como superior, con cursos prácticos especiales para la enseñanza agrícola, industrial, comercial o marítima, de acuerdo con la ubicación de las escuelas, y que se reconoce también como un embrión de formación. En este artículo se pretende estudiar cómo las escuelas normales primarias abordaron la formación en estas áreas entre 1844 y 1926 y, en particular, saber cómo la enseñanza de las matemáticas en esas escuelas se adaptó a esta finalidad.

Palabras clave: Historia de la enseñanza de las matemáticas. Enseñanza profesional. Enseñanza primaria. Escuelas normales. Formación de professores. 


\section{INTRODUÇÃO}

O estudo histórico do ensino primário durante o século XIX português não costuma prestar muita atenção à vertente de formação profissional destinada aos discentes, preferindo temas como a profissionalização docente, a consolidação deste subsistema de ensino através da burocracia escolar ou estudar os modos como uma formação básica obrigatória (em especial o ler, escrever e contar) se foi constituindo. Quanto aos conteúdos, os estudos costumam pressupor que este ensino primário se destinaria a uma preparação geral não contemplando formações profissionais específicas. Os alunos que se mantivessem no sistema de ensino após o ensino primário poderiam completar a formação para o exercício de uma profissão nas escolas profissionais, ou continuar para o ensino secundário.

E no entanto, quando observamos com mais atenção a legislação, encontramos a preocupação com uma formação que prepare para o exercício futuro de uma profissão. Detectamos isso, através da presença de temas relacionados com a agricultura, a agrimensura, a contabilidade etc. Este texto pretende estudar os temas curriculares, em particular os ligados à matemática, que remetem para os usos profissionais presentes no ensino primário português. $\mathrm{O}$ estudo centrar-se-á na consulta de legislação desde 1844, data da primeira reforma do ensino primário que refere esse tipo de ensino, e 1926, ano da extinção das escolas primárias superiores. Em trabalhos anteriores estudamos a evolução da matemática escolar no ensino primário (ALMEIDA; CANDEIAS, 2014) e nas escolas profissionais (RODRIGUES, 2014). Aqui, destacando os programas e a formação de professores para o ensino primário, começaremos por estudar a evolução do segundo grau do ensino primário, e a criação de um terceiro grau. Terminaremos com uma atenção especial às escolas primárias superiores. Tal como noutros trabalhos, focaremos a nossa atenção nos temas relacionados com a matemática e o seu ensino.

\section{O 20 GRAU DO ENSINO PRIMÁRIO}

A Reforma da Instrução Primária, de Costa Cabral (1844) separa, pela primeira vez, o ensino primário em dois graus sequenciais. Após o $1^{\mathrm{O}}$ grau, destinado a crianças a partir dos sete anos e centrado na aprendizagem da leitura, da escrita, de princípios morais básicos, e de operações matemáticas simples - o usual "ler, escrever e contar ${ }^{1 "}$-, era estabelecido um $2^{2}$ grau que continha, entre outros, os tópicos desenho linear, aritmética e

\footnotetext{
${ }^{1}$ Os tópicos propostos para o 1 o grau eram: ler, escrever e contar; princípios gerais de moral; doutrina cristã e civilidade; exercícios gramaticais; princípios de corografia, e história portuguesa.
}

geometria com aplicação à indústria e escrituração ${ }^{2}$. O $1^{\mathrm{O}}$ grau seria ensinado nas escolas primárias existentes e para o $2^{\mathrm{o}}$ seriam estabelecidas novas escolas, sendo dada preferência aos concelhos que oferecessem casa e mobília para a instalação do estabelecimento.

A referência à "aplicação à indústria e escrituração" constitui a primeira vez que, no ensino primário português, se introduzem tópicos que vão para além do que era considerado ensino básico. Até então, após uma formação no ensino primário, os alunos podiam continuar os seus estudos em escolas secundárias denominadas liceus que, após sete anos de escolaridade davam acesso à universidade. $\mathrm{O}$ currículo destes estabelecimentos visava essencialmente a preparação para os estudos superiores, privilegiando pois uma formação de âmbito geral que compreendia as línguas (essencialmente português, francês e inglês), o estudo das ciências (matemática, física, química, biologia etc.), e outras disciplinas. No entanto, esse percurso apenas estava disponível para uma escassa minoria de alunos, essencialmente os de maiores posses e com acesso aos poucos liceus existentes. Como veremos, a disponibilização de um ramo do ensino primário de cariz profissionalizante vai pois procurar captar um leque de alunos que, embora desejando expandir a sua formação, não encontravam nos liceus uma formação próxima da requerida para uma entrada no mundo do trabalho.

Em um contexto de quase inexistência de escolas profissionais, que só vão conhecer alguma expansão no último quartel do século XIX (RODRIGUES, 2014), podemos atribuir a criação deste novo $2^{\circ}$ grau do ensino primário em 1844 , por um lado, à necessidade de aprofundamento de uma formação generalista em gramática, matemática, história e temas religiosos e, por outro, à intenção de possibilitar alguma formação profissional para ocupações ligadas ao pequeno comércio e indústria locais ou ao melhoramento agrícola. O cuidado com esses tipos de ocupações profissionais está expresso na inclusão de temas de contabilidade, bem como nos temas matemáticos destinados à "aplicação à indústria". Não sabemos os conteúdos específicos que o legislador imaginava para esses novos temas, pois apenas em $1850 \mathrm{se}$ explicita que o ensino do desenho linear deveria começar por linhas e ângulos e continuar depois por outras figuras, "desde as mais usuais, até às mais difíceis, de vasos, molduras, elevações, desenhos de máquinas, e outras aplicações complicadas" (PORTUGAL, 1851, p.902) não havendo recomendações para o ensino de temas matemáticos.

Com pequenas alterações, esta estrutura do ensino primário vai manter-se até 1894 . Em 1850, por exemplo, o tema matemático do $2^{\circ}$ grau passa a denominar-se Aritmética

\footnotetext{
${ }^{2}$ Os tópicos propostos para o 2 o grau eram: gramática portuguesa; desenho linear; geografia e história geral; história sagrada do antigo e novo testamento; aritmética e geometria com aplicação à indústria; escrituração.
} 
e Geometria com aplicação às artes e explicita-se que na escrituração se discutirão partidas singelas e dobradas.

Um dos textos que nos permite compreender as tendências da época é o decreto que contém a falhada reforma educacional de António da Costa, promulgada e revogada em 1870, que tem, apesar da sua curta vida, o mérito de explicitar uma visão inovadora e desassombrada para o sistema de ensino português. Armado de estatísticas que comparavam os sistemas de ensino de países europeus e dos Estados Unidos, António Costa mostra o considerável atraso do investimento social e econômico na educação e, num bem estruturado decreto, propõe uma reforma "radical" (PORTUGAL, 1871, p.459) para o ensino primário.

Para além de propor uma descentralização do sistema escolar, atribuindo aos municípios a responsabilidade pelo ensino primário, o $1^{\mathrm{O}}$ e o $2^{\underline{\mathrm{O}}}$ grau do ensino primário seriam agora designados, respectivamente, por elementar e complementar. Enquanto as escolas primárias elementares seriam estabelecidas nas freguesias, as escolas primárias complementares só se localizavam nas sedes dos concelhos ${ }^{3}$.

No que se refere ao objetivo deste texto, a legislação de António da Costa reforça a componente de formação profissional para o ensino primário, que ele assinala como uma das deficiências nacionais. Assim, na sua proposta, o ensino primário masculino prevê a formação integral do estudante em quatro aspectos fundamentais: educação física, educação moral, educação intelectual e educação política, estando a formação profissional essencialmente incluída na educação intelectual. Faziam parte do currículo

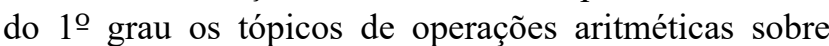
números inteiros e decimais, desenho linear, noções de agricultura. É a primeira vez que temas mais específicos do que o tradicional ensino básico generalista são incluídos na formação primária inicial. Quanto ao $2 \mathrm{O}$ grau, incluemse os temas de aritmética e geometria elementar e as suas aplicações mais comuns, desenho linear e suas aplicações, escrituração e agrimensura, embora os dois últimos fossem objeto de ensino especial, de acordo com as localidades onde a escola se encontrava. No ensino primário feminino não eram lecionadas noções de agricultura ou agrimensura, mas integrava o currículo o tema de coser, fazer meia, marcar, talhar e economia doméstica e no $2^{\circ}$ grau escrituração, fazer rendas, flores e outros lavores próprios do sexo, conforme as condições da localidade.

As propostas de António da Costa são feitas num contexto, o fontismo, de grande investimento público nos transportes e nas vias de comunicação como fator de desenvolvimento do país (CARVALHO, 2008). Apesar da revogação precoce das suas propostas, a preocupação com

\footnotetext{
${ }^{3}$ O sistema administrativo português da época previa concelhos que se subdividiam em freguesias, que grosso modo correspondiam às paróquias, divisões administrativas da Igreja Católica.
}

um $2^{\mathrm{o}}$ grau do ensino primário que fornecesse uma pequena formação profissional manteve-se. Assim, a Carta de Lei de 1878, da autoria de Rodrigues Sampaio, para além de retomar os temas matemáticos previstos na legislação revogada de 1870, acrescenta que após três anos o ensino complementar deverá incluir, para o sexo masculino, escrituração e princípios de economia rural, industrial ou comercial, de acordo com as necessidades locais e, para o sexo feminino, desenho de ornato e escrituração.

Conseguimos ter uma ideia do grau de aprofundamento dos conteúdos matemáticos do $2^{\mathrm{O}}$ grau propostos em 1878 recorrendo ao Regulamento para a execução de leis sobre a instrução primária de 1881 que, seguindo as ideias de 1878 da reforma de Rodrigues Sampaio, muito próxima das ideias de António da Costa (PROENÇA, 1997), detalha os conteúdos exigidos nos exames finais do ensino primário complementar. Os exames iniciavamse pelas provas escritas e, no que se refere aos temas matemáticos, os alunos deveriam executar a "prática de uma operação aritmética em frações ordinárias ou decimais, e solução de um problema, de aplicação da regra de três" (PORTUGAL, 1882, art. 80). Quanto às provas orais, os candidatos deveriam realizar a "resolução no quadro preto de operações de aritmética compreendidas no programa das escolas complementares, [...] desenho no quadro de uma figura geométrica ou resolução de um problema simples de geometria" (art. 93).

O Quadro 1 sintetiza os temas relacionados com matemática no $2^{\circ}$ grau do ensino primário incluídos na legislação entre 1844 e 1878.

Quadro 1 - Temas relacionados com matemática no $2^{\underline{0}}$ grau do ensino primário por decreto (1844-1878)

\begin{tabular}{|c|l|l|}
\hline Ano & $\begin{array}{l}\text { Temas relacionados com } \\
\text { matemática }\end{array}$ & $\begin{array}{l}\text { Outros temas } \\
\text { profissionalizantes }\end{array}$ \\
\hline 1844 & $\begin{array}{l}\text { Desenho linear } \\
\text { Aritmética e geometria com } \\
\text { aplicação à indústria }\end{array}$ & Escrituração \\
\hline 1850 & $\begin{array}{l}\text { Aritmética e geometria com } \\
\text { aplicação às artes }\end{array}$ & $\begin{array}{l}\text { Escrituração por partidas } \\
\text { singelas e dobradas }\end{array}$ \\
\hline $\begin{array}{l}\text { Sistema legal de pesos e } \\
\text { medidas } \\
\text { Desenho linear e suas } \\
\text { aplicações } \\
\text { Masculino: Aritmética e } \\
\text { geometria elementar e as suas } \\
\text { aplicações mais comuns }\end{array}$ & $\begin{array}{l}\text { Escrituração } \\
\text { Masculino: Agrimensura } \\
\text { Feminino: Fazer rendas, } \\
\text { flores e outros lavores } \\
\text { próprios do sexo }\end{array}$ \\
\hline $\begin{array}{l}\text { Aritmética e geometria } \\
\text { elementar e suas aplicações } \\
\text { mais usuais } \\
\text { Sistema legal de pesos e } \\
\text { medidas } \\
\text { Desenho linear e suas } \\
\text { aplicações mais comuns }\end{array}$ & $\begin{array}{l}\text { Noções elementares de } \\
\text { agricultura } \\
\text { (Passados 3 anos: } \\
\text { Masculino: Escrituração, } \\
\text { Princípios de economia rural, } \\
\text { industrial ou comercial } \\
\text { Feminino: Desenho de } \\
\text { ornato, Escrituração) }\end{array}$ \\
\hline
\end{tabular}

Fonte: PORTUGAL, 1845, 1851, 1871, 1879. 


\section{ForMAÇÃo DE PROFESSORES E O 20 GRAU DO ENSINO PRIMÁrIO}

Apesar de estar previsto desde 1835, apenas em 1860 se inicia o estabelecimento de um sistema coerente de escolas destinadas à formação de professores para o ensino primário (CANDEIAS, 2018). Diversos diplomas legais, no entanto, permitem-nos conhecer as visões dos governantes quanto a este tipo de escolas, mesmo que elas não tenham passado de intenções. O Regulamento da Escola Normal Primária do Distrito de Lisboa (1845), publicado logo após a reforma de 1844 , diferenciava a formação de professores para o $1^{\mathrm{O}}$ e o $2^{\mathrm{O}}$ grau do ensino primário (CANDEIAS, 2018). Os futuros docentes do 1 o grau frequentariam, entre outras, as disciplinas de Aritmética com a extensão possível, Desenho Linear e contactariam com Os primeiros elementos e noções indispensáveis para os exercícios agronómicos e, no segundo ano, a disciplina de Geometria com aplicação à industria. Já os futuros docentes do $2 \underline{0}$ grau frequentariam, entre outras, as disciplinas de Desenho Linear, Geometria com aplicação à indústria e Escrituração. Para além da instrução teórica, estava prevista a prática de exercícios agronômicos, em um terreno onde se estabeleceria um jardim de sementeiras e viveiros de plantas, árvores e arbustos, para o ensino elementar de horticultura, jardinagem e arboricultura.

A homogeneização gradual do sistema escolar que ocorreu ao longo do século XIX e que formalizou o ensino secundário (BARROSO, 2005) também levou a uma estruturação da formação de professores do ensino primário que se inicia com a publicação do Regulamento para a Escola Normal Primária de Lisboa, em 1860, seguida pela entrada em funcionamento da Escola Normal Primária de Marvila, Lisboa, em 1862. Esta escola, em regime de internato apoiado pelo Estado, destinada à formação de professores do sexo masculino destinados ao ensino primário, foi a primeira integrada num plano mais amplo de formação de professores para este ciclo.

Uma escola normal para o sexo feminino foi regulamentada em 1863, mas só entrou em funcionamento, também em regime de internato, em 1866, em uma casa de recolhimento situada em Lisboa (PINTASSILGO, 2012).

O Regulamento de 1860 mantém a separação entre os cursos de professores destinados ao $1^{\mathrm{O}}$ e ao $2^{\mathrm{O}}$ grau de ensino primário já proposta em 1845 . Enquanto que os do $1 .^{\circ}$ grau frequentariam as disciplinas de Aritmética, compreendendo as proporções e a sua aplicação aos usos da vida, Sistema legal de pesos e medidas e Desenho linear e as suas aplicações mais úteis na vida comum, os futuros docentes destinados ao $2^{\mathrm{O}}$ grau frequentariam ainda Continuação do desenho linear, compreendendo noções elementares de geometria e suas aplicações práticas,
Noções de agricultura e Elementos de escrituração mercantil e agrícola: redação de papéis oficiais a que é obrigado o professor primário, entre outras. Para além da instrução teórica, mantém-se a intenção de incluir a prática de exercícios agronômicos e exercícios de aplicação da geometria à agrimensura nos seus processos mais simples e comuns. $\mathrm{O}$ ensino das noções de agricultura seria dado pelo encarregado dos trabalhos agrícolas da quinta anexa à escola.

No final da década de 1860 ocorreram tentativas para alargar o âmbito do ensino normal, que então se reduzia ao de Lisboa e a poucas escolas normais de ensino mútuo. Assim, no início de 1869 procurou-se associar o ensino normal a alguns liceus, criando nesses, cadeiras de Pedagogia, propondo a consequente extinção da escola de Lisboa. No final do mesmo ano optou-se por outro caminho, criando escolas normais em Lisboa, Porto, Coimbra, Évora e Viseu e extinguindo as escolas normais de ensino mútuo ainda existentes. Em 1870 foram criadas duas escolas normais femininas em Lisboa e Porto (GOMES, 1996).

A partir de meados da década de 1890 assistiu-se a um processo de diferenciação entre as escolas normais, instituindo-se escolas de habilitação para o magistério de professores do ensino primário nas capitais de distrito do país que ofereciam uma formação simplificada e com carácter regional, relativamente às escolas normais consideradas de referência (Lisboa, Porto e Coimbra) (PINTASSILGO, 2012). A partir de 1896 (PORTUGAL, 1897), os candidatos a professores que não tivessem frequentado as escolas normais passavam a ter que fazer exames perante essas instituições. Estes exames tinham como referência os programas das escolas normais. $\mathrm{O}$ quadro 2 sintetiza a arquitetura do sistema de formação de professores para o ensino primário até 1911 e que, com pequenas alterações, se vai prolongar até 1926.

Quadro 2 - Momentos principais das instituições de formação de professores para o ensino primário (1844-1911)

\begin{tabular}{|l|l|}
\hline Ano & $\begin{array}{l}\text { Momentos principais das instituições de formação de } \\
\text { professores para o ensino primário em Portugal }\end{array}$ \\
\hline 1844 & Intenções de criação de escolas normais \\
\hline 1860 & $\begin{array}{l}\text { Criação da Escola Normal Primária do Distrito de Lisboa. } \\
\text { Começa a funcionar em 1863 }\end{array}$ \\
\hline 1863 & $\begin{array}{l}\text { Criação de uma escola normal primária para o sexo } \\
\text { feminino. Começa a funcionar em 1866 }\end{array}$ \\
\hline 1869 & $\begin{array}{l}\text { São criadas cinco escolas normais para a formação de } \\
\text { professores de instrução primária em Lisboa, Porto, } \\
\text { Coimbra, Évora e Viseu }\end{array}$ \\
\hline 1881 & $\begin{array}{l}\text { Escolas normais de primeira classe em Lisboa e Porto, e } \\
\text { de segunda classe noutros distritos do país }\end{array}$ \\
\hline 1911 & $\begin{array}{l}\text { Os professores das escolas normais passam a ser formados } \\
\text { nas Escolas Normais Superiores }\end{array}$ \\
\hline
\end{tabular}

Fonte: PORTUGAL, 1845, 1861, 1864,1870, 1882, 1911. 
A partir de 1881 surgiram nos currículos das escolas normais disciplinas de Metodologia, onde se abordavam os aspetos pedagógicos. A introdução dessas disciplinas marca o desenvolvimento de um saber pedagógico específico para o ensino primário, que vai materializar nos manuais que então começam a ser produzidos e que nos permitem vislumbrar o seu desenvolvimento autónomo. Esta inovação coincide com o desenvolvimento do ideário da Escola Nova e com a procura de uma fundamentação científica para os métodos educacionais (MATOS, 2014).

Em 1910, no final da Monarquia existiam seis escolas normais em Lisboa, Porto e Coimbra (uma para cada sexo em cada uma destas cidades) e 17 escolas de habilitação para o magistério primário, nas capitais de distrito, exceto Santarém. Essa rede de escolas era vista como um sobredimensionamento do sistema, já que se diplomavam mais professores do que era julgado necessário, muitos ficando desempregados ou exercendo atividades não relacionadas com a docência. Essa situação prolongarse-ia até 1921, quando as escolas enquadradas na reforma de 1901 foram encerradas e substituídas pelas novas instituições republicanas (PINTASSILGO, 2012).

Apesar de se considerar que estavam a ser formados demasiados professores para o ensino primário, na realidade a percentagem de analfabetismo na população portuguesa da época era muito superior a de países europeus com um desenvolvimento econômico similar. De acordo com Carvalho (1996), os números do analfabetismo constituíam uma calamidade e uma vergonha nacional, sendo analfabeta cerca de $82,4 \%$ da população portuguesa em 1878 e $75 \%$ em 1911 . Referindo-se aos dados de meados da década de 1860 , António Candeias (2005) salienta que a percentagem de crianças inscritas no ensino primário elementar também apresentava números muito inferiores, comparativamente com outros países europeus.

\section{UM TERCEIRO GRAU PARA O ENSINO PRIMÁRIO}

Em 1894, sob a supervisão de Jaime Moniz, a parte do sistema educativo português que preparava o acesso à universidade sofre um conjunto de ajustamentos estruturais, muito deles sobrevivendo até à atualidade (PROENÇA, 1997). No caso do ensino primário, o Decreto $\mathrm{n}$ - 1 (PORTUGAL, 1894) pretende estabelecer em um só documento as bases de um plano harmonioso de administração desta tipologia de ensino, e tem como principal objetivo uma reorganização de recursos, com um propósito economicista. Esta reforma contraria a anterior (de Rodrigues Sampaio, em 1878) que tinha estabelecido a descentralização do ensino, voltando a apostar em uma política de centralização dos serviços no Estado.

Com o argumento do aperto das finanças públicas e de que o ensino primário complementar tinha poucos alunos, a reforma de 1894 reduz significativamente o número de escolas destinadas a esse ensino. Segundo o decreto, o ensino primário complementar, por um lado, fornece uma via profissionalizante e, por outro, permite o acesso às escolas de formação de professores primários. Vai ainda dividir o ensino elementar em dois graus de escolaridade obrigatória iniciados aos 6 anos de idade, e determinar que o $2^{\mathrm{o}}$ grau é preparatório para a frequência de estudos de nível secundário. Podemos apreciar no Quadro 3 a sequência dos temas relacionados com matemática no ensino primário propostos pela legislação de 1894.

$\mathrm{Na}$ legislação de 1894 opta-se por concentrar as escolas primárias complementares nas "sedes de liceus, nas cidades, e em todas as povoações cuja população exceda as 4.000 almas" (PORTUGAL, 1894, art. 11) e, como essas povoações não teriam como principais necessidades a formação relacionada com a agricultura, este tema desaparece, embora se mantenha a contabilidade e a escrituração. A intenção é, pois, a de providenciar uma formação profissional adaptada às pequenas empresas locais: predominantemente agrícolas nas pequenas vilas, e de vertente comercial nas maiores.

O Regulamento Geral do Ensino Primário de 1896, que completa a legislação de 1894, vai conter, pela primeira vez, um programa para o $2^{\mathrm{O}}$ grau do ensino primário. Nele se propõe que o ensino da aritmética deva ser essencialmente prático, ampliando-se os conhecimentos adquiridos no $1^{\mathrm{O}}$ grau, explicando com exemplos, e por meio de processos intuitivos, as definições

Quadro 3 - Temas relacionados com matemática no ensino primário por grau (1894)

\begin{tabular}{|c|c|c|c|}
\hline \multirow[b]{3}{*}{$\begin{array}{l}\text { Temas relacionados } \\
\text { com matemática }\end{array}$} & \multicolumn{2}{|c|}{ Ensino primário elementar } & \multirow{2}{*}{ Ensino primário complementar } \\
\hline & 10 grau & 2o grau & \\
\hline & $\begin{array}{l}\text { - Operações fundamentais de } \\
\text { aritmética e noções do sistema legal } \\
\text { de pesos e medidas } \\
\text { - Elementos de desenho }\end{array}$ & $\begin{array}{l}\text { - Aritmética e geometria elementares } \\
\text { - Desenho linear }\end{array}$ & $\begin{array}{l}\text { - Aritmética e geometria elementares e } \\
\text { suas aplicações } \\
\text { - Noções de economia, contabilidade e } \\
\text { escrituração } \\
\text { - Desenho linear e de ornato }\end{array}$ \\
\hline Outros temas & - Trabalhos manuais & & \\
\hline
\end{tabular}

Fonte: Decreto no 1 (PORTUGAL, 1894). 
que tenham de ser introduzidas Se na aritmética e no estudo do sistema métrico se propõe um aprofundamento dos temas estudados no 1 o grau, a geometria é um tema que só está presente no 2 o grau. Estudam-se volumes, superfícies, linhas paralelas e perpendiculares, ângulos, círculo, polígonos e sólidos. Recomenda-se que o ensino da geometria seja sempre prático.

Em 1896, pela primeira vez são publicados, anexos ao Regulamento Geral do Ensino Primário, programas para o ensino complementar. Apresentados como sendo uma sequência dos do $2^{\circ}$ grau, desenvolvem os temas do ensino elementar e acrescentam alguns tópicos. A aritmética inclui: raízes, estudo da divisibilidade, números primos, regras de proporcionalidade, regras de três simples e compostas, estudo de temas de contabilidade (descontos, compra e venda de fundos públicos, ações e obrigações, câmbios). A geometria é também abordada com mais detalhe e inclui construções geométricas.

O Regulamento Geral do Ensino Primário de 1896 inclui na sua II Parte especificações para os exames finais do ensino primário complementar. Os temas relacionados com matemática das provas escritas eram: a resolução de operações aritméticas ou de problemas de aritmética e de contabilidade e escrituração comercial (uma hora). A prova de desenho consistia na construção de duas figuras de desenho linear e um desenho à vista ou por cópia. $\mathrm{Na}$ prova oral, o candidato deveria resolver exercícios práticos no quadro preto e responder a questões sobre aritmética, geometria e escrituração.

A entrada no século XX trouxe força aos propagandistas republicanos, com novas adesões que engrossavam as hostes da sua militância contra o sistema monárquico (CARVALHO, 2008). É neste contexto que o Governo do início do século, presidido por Hintze Ribeiro, em uma tentativa de vitalizar as instituições, legislou sobre diferentes serviços do Estado, desde os serviços de saúde, telégrafos, correios, fazenda pública, entre outros. Entre os documentos oficiais encontram-se propostas de reforma da educação, entre as quais a organização do ensino elementar industrial e comercial e uma nova reforma do ensino primário (CARVALHO, 2008). Assim, o Decreto no 8 de dezembro de 1901 cria restrições no acesso ao emprego público a quem não tenha diploma do ensino primário e estabelece penalizações para os funcionários públicos que, após cinco anos da publicação do decreto, não tivessem obtido certificado de habilitação do $1^{\circ}$ grau do ensino primário. Esse decreto também traz alterações no que respeita à organização pedagógica do ensino primário, extinguindo o ensino primário elementar, simplificando a leitura e a aritmética e cortando os trabalhos manuais dos programas "pela dificuldade de estabelecer entre nós o ensino técnico, como tem sucedido aliás na maioria dos países, onde a sua realização não passou ainda do papel, se excetuarmos algumas escolas, especialmente montadas para esse fim" (PORTUGAL, 1901, p. 1230).

$\mathrm{O}$ tom geral das recomendações curriculares da legislação de 1901 é o de uma simplificação dos conteúdos e reforço da ligação às aplicações dos conceitos. Por exemplo, na aritmética afirma-se "encaminhamos o seu estudo de modo a facilitar a aplicação vulgar dos números" (PORTUGAL, 1901, p. 1230). No $1^{\circ}$ grau, o programa requer que, quer as operações fundamentais da aritmética, quer o estudo do sistema métrico tenham especial atenção a pesagens e medições. Apesar da extinção do ensino primário complementar, a legislação de 1901 reforça a componente de formação profissional nos restantes graus: no $1^{\mathrm{o}}$ grau, o programa integra os temas de Rudimentos de agricultura prática e, no $2^{\circ}$, inclui os Rudimentos de ciências naturais, especialmente aplicáveis à agricultura e à higiene.

Os programas são publicados em outubro de 1902 e é possível verificar que no desenho da 4 a classe se pretende que o aluno aprenda a elaborar mapas para o auxílio da aprendizagem da geografia, designada à data por "corografia". A aprendizagem da agricultura está configurada apenas para a 3a e a 4⿳亠丷a classe e considerase que este ensino deverá ter um caráter o mais prático possível, integrando no último ano rudimentos de ciências naturais.

\section{FORMANDO PROFESSORES PARA UM $3^{\underline{0}}$ GRAU DO ENSINO PRIMÁrIO}

Embora o ensino primário complementar tenha sido criado em 1894, como vimos na secção anterior, apenas em 1896 a legislação aborda as alterações a efetuar na formação de professores. Na segunda parte do Regulamento Geral do Ensino primário de 1896, definiamse três formas de obter a habilitação para o magistério primário: a) cursando as escolas normais, b) frequentando os cursos distritais de habilitação para o magistério primário ministrados nas escolas complementares distritais e organizadas pelo governo, c) fazendo exame perante as escolas normais, ou perante as escolas distritais de habilitação para o magistério primário.

O Regulamento Geral do Ensino Primário de 1896 determina que em cada escola normal haveria dois cursos: um de dois anos, para a habilitação dos professores do ensino primário elementar, outro, de três anos, para a dos professores do ensino complementar. Os programas das disciplinas destes cursos repetem em dois anos as matérias do ensino primário, e acrescentam um terceiro ano que introduz novos tópicos. Os programas para a formação de professores do ensino complementar são uma sequência dos do curso normal para o $2^{\mathrm{O}}$ grau e acrescentam 
alguns tópicos: raízes, estudo da divisibilidade, números primos, regras de proporcionalidade, estudo de temas de contabilidade e logaritmos. A geometria é também abordada com mais detalhe e inclui construções geométricas.

Como vimos na secção anterior, apesar de a legislação de 1901 ter eliminado o ensino complementar, reforçou a ligação profissionalizante de alguns dos temas do ensino primário. Essa orientação também se detecta nos programas para as escolas normais de 1896 que integram as disciplinas: Caligrafia. Desenho linear e de ornato. Desenho de mapas. Noções de escrituração comercial $e$ agrícola. Elementos de ciências naturais e suas aplicações à agricultura è̀ higiene e Noções elementares de agricultura prática.

Após a eliminação do ensino primário complementar, em dezembro de 1902 são publicados novos programas para o ensino normal. Centrando-nos apenas nos conteúdos de caráter profissionalizante, destacamos que no tema Noções de escrituração comercial, industrial e agrícola incluído na disciplina Aritmética Prática e Geometria Elementar são lecionados os seguintes conteúdos:

No $1^{\circ}$ ano: contas fundamentais da escrituração; livros: diário, razão, caixa, inventários e balanço, ativo e passivo; livros auxiliares; sistemas de escrituração: partidas simples, partidas dobradas, débito e crédito.

No 2 ano: sociedades em nome coletivo $e$, comandita; sociedades anónimas; ações e obrigações; juro, dividendo, aluguer e renda; lei que rege os atos do comércio; seguros marítimos e terrestres; outras formas de previdencia; sociedades cooperativas; caixas económicas e livretes.

No 3 o ano: modelos de contas correntes, métodos direto e indireto, faturas, cheques, livranças; letra de câmbio, sacador, sacado, tomador e portador; bancos.

Embora se recomende que todas as noções de escrituração comercial sejam tratadas de forma muito sumária, estes tópicos apontam para um aprofundamento de temas comerciais muito para além do que poderíamos esperar que fossem as necessidades de lecionação do tema no ensino primário.

Em desenho linear, ao longo dos três anos pretendese a resolução gráfica dos problemas compreendidos nas noções de geometria dadas na respetiva cadeira e a lecionação de noções básicas de perspectiva e cópia de sólidos geométricos.

As noções de agricultura prática são lecionadas no 3 oㅡ ano de formação e contemplam os seguintes conteúdos: solos e terras aráveis; constituição elementar das terras aráveis; caracteres mecânicos, físicos e químicos; operações mecânicas da cultura da terra, instrumentos aratórios; condições quimicas da fertilidade das terras aráveis; esterco e adubos; noções gerais sobre a cultura das gramineas, leguminosas e raízes alimentares; prados e pastagens; afolhamentos e pousios; animais domésticos, seu tratamento e utilização; insetos úteis - apicultura e sericultura; fabricação do queijo e manteiga; princípios de horticultura; plantas têxteis, linho e cânhamo, sua cultura, colheita e preparo; árvores frutiferas; sua cultura, sementeira, mergulhia, excertos, plantação, tratamento dos pomares novos, poda; princípios de viticultura e vinificação.

Em todos esses exemplos estamos perante formações especializadas com um aprofundamento muito para além do que se esperaria ser necessário para lecionar o ensino primário. A ideia que fica é a de que todos estes legisladores esperavam que, através dos professores primários, fosse possível difundir no conjunto do território um conjunto de saberes profissionais necessários ao progresso nacional.

\section{A REPÚblica e AS ESCOLAS PRIMÁrIAS SUPERIORES}

Com a República, proclamada a 5 de outubro de 1910, surge o projeto de reformar a mentalidade portuguesa e uma das vias para a sua execução seria a da instrução e da educação dos cidadãos (CARVALHO, 2008). Através da leitura do preâmbulo do Decreto Regulamentador do Ensino Primário, publicado em 1911 e que reflete o ideário republicano para a educação, notamos que se continuam a valorizar as competências profissionais dos alunos. Aí pode ler-se:

A criança, de hoje para o futuro, conhecerá os rudimentos das artes, a agricultura, do comércio, da indústria, familiarizando-se, numa educação essencialmente prática, com a terra e com os utensílios que o homem põe ao serviço da vida (PORTUGAL, 1911, p. 1342).

O texto legislativo separa o ensino primário em três níveis: elementar, complementar e superior. $\mathrm{O}$ ensino primário elementar só pode ser iniciado quando a criança tem sete anos de idade, ter a duração de três anos, e prever o ensino dos produtos mais comuns da natureza, empregados na agricultura e indústria e nos trabalhos manuais e agrícolas, conforme os sexos e as regiões. Por sua vez, o ensino complementar é frequentado por crianças com idades superiores aos 10 anos de idade e tem a duração de dois anos. Neste grau de ensino, são lecionadas noções elementares de economia rural ou fabril, conforme a região, e noções elementares de aritmética, geometria, ciências físico-químicas e histórico-naturais, especialmente aplicáveis à industria, agricultura e astronomia descritiva. Os alunos aprendem ainda trabalhos manuais ou agrícolas, conforme os interesses regionais. 
Este diploma é um documento notável. Segundo Rómulo de Carvalho:

é uma reforma de sonho, em que se programa o que seria bom ver realizado, sem se atender à situação real do país, à sua pobreza sem remédio, à impreparação dos seus executores, à sonolência dos serviços do Estado, à inércia nacional" (CARVALHO, 2008, p. 666).

O ensino primário superior agora criado, tem a duração de três anos, exige para a sua frequência um diploma do ensino primário complementar e idade mínima de 12 anos de idade. Este curso, implementado pela primeira vez com características que o aproximam do curso secundário generalista dos liceus, inicia-se com três anos, e inclui cursos práticos especiais para o ensino agrícola, industrial, comercial ou marítimo, consoante as necessidades das regiões às quais as escolas pertençam.

Apesar das boas intenções republicanas, as escolas primárias superiores só foram efetivamente instaladas em 1919 por meio do Decreto no 5.787-A, que refina os planos curriculares de 1911. Agora estas escolas eram definidas como "institutos de educação geral e de preparação técnica de carácter regional" (PORTUGAL, 1919a, p. 1346A), e o seu curso continha dois tipos de secções. A seção geral incluía, entre outras, as disciplinas de matemática elementar, geometria intuitiva e sistema métrico; noções práticas de higiene e puericultura; modelação e desenho; e trabalhos manuais. O diploma estipulava ainda que as escolas teriam em funcionamento todas ou algumas das seguintes seções técnicas: seção agrícola, secção doméstica, seção industrial e secção marítima. Para lecionar a componente técnica nestas escolas seriam contratados professores, consoante as necessidades, havendo professores efetivos apenas para a lecionação da componente geral.

Em novembro do mesmo ano são publicados os programas das disciplinas do ensino primário e do ensino primário superior (PORTUGAL, 1919b. Estes programas especificam as disciplinas de Noções de economia, Matemática elementar (aritmética, geometria, álgebra e agrimensura), Contabilidade, Ciências físico-químicas e histórico-naturais e suas aplicações à agricultura, ao comércio e às indústrias, consoante às necessidades de cada região e Desenho. No âmbito da matemática, o programa explicita ao pormenor cada tema, incluindo o número de aulas que lhe são dedicadas, fazendo referências ao modo como o aluno assimilará os vários conceitos. $\mathrm{O}$ programa de geometria incluía ainda um apêndice sobre cosmografia. Os temas tratados aproximam estas escolas do curso lecionado nos liceus da época.

Prevê-se que, neste nível de ensino, uma grande parte do tempo letivo seja exclusivamente consagrado a trabalhos de aplicação e exercícios práticos. O certificado do curso de ensino primário superior habilita para a matrícula nas escolas normais primárias, para os cursos regulares das escolas industriais, agrícolas, comerciais, profissionais e técnicas e para a matrícula na classe correspondente do curso dos liceus.

\section{A FORMAÇÃo doCENTE PARA AS ESCOLAS PRIMÁrIAS SUPERIORES}

Em 1914, com a pretensão de melhorar a sua qualidade, o ensino normal é concentrado em três escolas normais em Lisboa, Coimbra e Porto (PORTUGAL, 1914), transformando as restantes escolas normais espalhadas pelo país em escolas primárias superiores que perdem portanto a sua qualidade de instituições de formação docente. O governo indicava, no entanto, que poderia criar outras escolas normais, com o mesmo modelo, a pedido das juntas gerais do distrito, desde que estas entidades tomassem a seu cargo todas as despesas de instalação e de material escolar, ficando os vencimentos a cargo do Estado.

As novas escolas normais tinham, como já era tradição, a finalidade de habilitar professores de ambos os sexos para o exercício do magistério primário, e as disciplinas distribuíam-se por três anos, compreendendo um curso teórico, comum aos dois sexos e cursos práticos, cursos específicos para cada sexo. As disciplinas do curso teórico eram de caráter generalista, prevendo uma aprendizagem académica transversal. Os cursos práticos integravam disciplinas de carácter tecnológico, nomeadamente: a) Desenho linear e projeções; b) Trabalhos manuais e modelação; e e) Noções de economia rural, jardinagem e horticultura. Foi em 1916, que foram promulgados os programas do elenco curricular publicado dois anos antes (PORTUGAL, 1916).

Em 1919 (PORTUGAL, 1919b) são alterados os programas destas escolas normais primárias, cujos cursos passam a ter a duração de quatro anos. $\mathrm{O}$ novo plano curricular prevê as disciplinas de Economia, Matemática (aritmética, álgebra e geometria elementar, agrimensura, contabilidade e escrituração comercial), Agricultura, Desenho e modelação e Conhecimentos Gerais acerca do comércio e indústria (contabilidade comercial, industrial e agrícola). Para o sexo masculino haverá lugar a que os futuros professores aprendam trabalhos manuais e agrícolas.

Encontramos no Decreto no 6.203 (1919c) os programas do curso normal primário oferecido pelas escolas normais, com correspondência às disciplinas que se ensinam no ensino primário, nas quais se incluem metodologias para ensinar e a preparação de futuros professores para ensinar. Na disciplina de "Matemáticas elementares" 
Este ensino tem por objeto: a) a revisão dos conhecimentos matemáticos já adquiridos pelos alunos, com o fim de os habilitar a ensinarem as primeiras noções da Aritmética e da Geometria com o indispensável rigor, e a prepararem eles próprios os exercícios e problemas que hão de propor mais tarde aos seus futuros discípulos (PORTUGAL, 1919c, p. 2340).

Para além dos conteúdos, o programa indica metodologias a adotar no ensino da aritmética, geometria e álgebra, recomendando a escolha de problemas sistematicamente mais difíceis e a formalidade da linguagem necessária para ensinar.

Por sua vez, a disciplina de Direito Usual e Economia Social prepara o futuro professor para que tenha um papel ativo e interventivo a nível social, de fato podemos ler que Economia Social

é a parte instrutiva da educação social respeitante aos conhecimentos econômico-jurídicos fundamentais que todo o cidadão deve possuir para ter uma consciência social completa da época e do lugar em que vive (PORTUGAL, 1919c, p. 2364).

e Direito Usual é

o conhecimento prático dos principais diplomas legais e das normas e formalidades jurídico-burocráticas, indispensável a todo o cidadão para exercer integralmente a sua função na sociedade, quer cumprindo deveres, quer defendendo direitos e tornando cada individuo capaz de ser um procurador de si próprio, perante as repartições públicas e o estado (PORTUGAL, 1919c, p. 2364).

O futuro professor aprendia ainda Economia doméstica, Noções de agricultura e economia rural e Modelação e desenho.

As Escolas Primárias Superiores tiveram uma vida atribulada. Em 1924 são extintas, sendo reabertas ainda no mesmo ano. A 15 de junho de 1926 (PORTUGAL, 1926), logo após o golpe militar de 28 de Maio de 1926 que pôs fim à I⿳亠口冋 República, são irreversivelmente extintas.

\section{CONSIDERAÇÕES FINAIS}

Pretendemos estudar os modos como as escolas de formação de professores do ensino primário português integraram as áreas de formação profissional e, em particular, saber como o ensino da matemática nessas escolas se adaptou a esta finalidade. Para isso, efetuamos um levantamento da legislação para o ensino primário e o ensino normal primário entre 1844 e 1930, procurando especificamente indícios de intenções curriculares profissionalizantes. Efetivamente, podemos constatar que quase todas as peças legislativas que consultamos previam alguma forma de formação profissional para o ensino primário, tendo inclusivamente sido previsto um $2^{o}$ grau ou um grau complementar do ensino primário aprofundando precisamente competências profissionais. Essa formação centrava-se especialmente em competências de contabilidade, ou escrituração, mas também incluía áreas como desenho técnico, agricultura, agrimensura, ou cosmografia. Apresentamos a conjectura de que esta formação, mais do que competir com a formação profissional ministrada nas escolas técnicas, essencialmente vocacionadas para servir a grande indústria, apostava na disseminação de competências para apoiar a pequena economia local: comerciantes, oficinas, pequenas empresas agrícolas etc. Os programas das disciplinas com alguma relação com a matemática espelham precisamente essa ligação, privilegiando temas mais ajustados ao apoio à aprendizagem desses saberes.

\section{REFERÊNCIAS}

ALMEIDA, M. C.; CANDEIAS, R. Os programas de matemática do ensino primário, da Telescola e do Ciclo Preparatório do Ensino Secundário. In:

ALMEIDA, António José; MATOS, José Manoel (coord.). A matemática nos programas do ensino não-superior (1835-1974). Caparica: UIED/APM, 2014. p. 39-68.

BARROSO, João. Políticas educativas e organização escolar. Lisboa: Universidade Aberta, 2005.

CANDEIAS, António. Modernidade, educação e estatísticas na ibero-américa dos séculos XIX e XX. Lisboa: EDUCA, 2005 .

CANDEIAS, R. A matemática na formação dos professores do ensino primário em Portugal da reforma pombalina de 1772 até 1910. In: MATOS, José Manoel (ed.). A matemática e o seu ensino na formação de professores: uma abordagem histórica. Lisboa: UIED, 2018. v. 1, p. 11-56. https://doi. org/10.5007/2175-795x.2016v34n1p41

CARVALHO, Rómulo de. História do ensino em Portugal desde a fundação da nacionalidade até ao fim do regime de Salazar-Caetano. 2. ed. Lisboa: Fundação Calouste Gulbenkian, 1986. https://doi.org/10.1017/ s0041977x00120178

GOMES, Joaquim Ferreira. O ensino da pedagogia e da psicologia nas escolas normais primárias (1862-1974). Revista Portuguesa de Pedagogia, [s.l.], v. 30, n. 2, p. 103-157, 1996.

MATOS, José Manoel. A matemática no ensino não-superior em Portugal. In: ALMEIDA, António José; MATOS, José Manoel (coord.). A matemática nos programas do ensino não-superior (1835-1974). Caparica: UIED/APM, 2014. p. 15-35. https://doi.org/10.11606/d.8.2007.tde-30112007155536 
PINTASSILGO, Joaquim (ed). Escolas de formação de professores em Portugal. Lisboa: Colibri, 2012.

PORTUGAL. Decreto com força de lei de 21 de maio. Cria escolas normais superiores junto das Faculdades de Letras e de Ciências das Universidades de Coimbra e de Lisboa de 21 de maio de 1911. Diário do Governo, Lisboa, n. 73, p. 1341-1347, 30 mar. 1911. https://doi.org/10.29094/ fishmed.2016.011

PORTUGAL. Decreto no 1. Reorganiza a Instrução Primária de 24 de dezembro de 1894. Lisboa: Imprensa Nacional, 1895. 9 (Coleção Oficial da Legislação Portuguesa, 1894). p. 1064-1076.

PORTUGAL. Decreto no 2.213. Regulamento e programas para o ensino normal primário de 10 de fevereiro de 1916. Diário do Governo, Lisboa, n. 24, p. 65-146, 10 fev. 1916.

PORTUGAL. Decreto no 11.730 . Extingue as Escolas Primárias Superiores a partir de 30 de Junho de 1926 de 15 de junho de 1926. Diário do Governo, Lisboa, n. 126, p. 578-579, 15 jun. 1926. https://doi.org/10.1590/s007402761926000200005

PORTUGAL. Decreto no 5.787-A. Aprova e manda pôr em execução o regulamento das escolas primárias superiores de 10 de maio de 1919. Diário do Governo, Lisboa, n. 98, p. 1346A-1346HH, 10 maio 1919a.

PORTUGAL. Decreto no 6.137. Regulamenta o ensino primário e normal de 29 de setembro de 1919. Diário do Governo, Lisboa, n. 198, p. 2068-2093, 29 set. 1919b.

PORTUGAL. Decreto no 6.203. Programas do ensino primário geral, do ensino primário superior, do ensino normal primário e do exame de admissão às Escolas Normais Primárias de 7 de novembro de 1919. Diário do Governo, Lisboa, n. 227, p. 2229-2385, 7 nov. 1919c. https://doi. org/10.11606/d.8.2014.tde-21012015-190807

PORTUGAL. Decreto no 8. Reforma do ensino primário e do ensino normal de 24 de dezembro de 1901. Lisboa: Imprensa Nacional, 1902. (Coleção Oficial da Legislação Portuguesa, 1901). p. 1229-1246.

PORTUGAL. Instruções e programa regulando o provimento dos lugares de mestras da escola normal primária do sexo feminino em Lisboa. Lisboa: Imprensa Nacional, 1865. (Coleção Oficial da Legislação Portuguesa, 1864). p. 2-5.

PORTUGAL. Lei no 233. Regulamento do ensino normal primário de 7 de julho de 1914. Diário do Governo, Lisboa, n. 111, p. 477-479, jul. 1914.

PORTUGAL. Programas das disciplinas do ensino primário de 18 de outubro de 1902. Lisboa: Imprensa Nacional, 1903a. (Coleção Oficial da Legislação Portuguesa, 1902). p. 1034-1040.
PORTUGAL. Programas para o ensino normal de 4 de dezembro de 1902. Lisboa: Imprensa Nacional, 1903 b. (Coleção Oficial da Legislação Portuguesa, 1902). p. 1276-1289.

PORTUGAL. Reforma da Instrução Primária de 16 de agosto de 1870. Lisboa: Imprensa Nacional, 1871. (Coleção Oficial da Legislação Portuguesa, 1870). p. 458-468.

PORTUGAL. Reforma do ensino primário de 2 de maio de 1878. Lisboa: Imprensa Nacional, 1879. (Coleção Oficial da Legislação Portuguesa, 1878). p. 53-62.

PORTUGAL. Reforma Geral dos Estudos de 20 de setembro de 1844. Lisboa: Imprensa Nacional, 1845. (Coleção Oficial da Legislação Portuguesa, 1844). p. 306-330.

PORTUGAL. Regulamento da Escola Normal Primária do distrito de Lisboa de 26 de outubro de 1845. Lisboa: Imprensa Nacional, 1846. (Coleção Oficial da Legislação Portuguesa, 1845). p. 923-930. https://doi.org/10.21011/ apn.2017.1505

PORTUGAL. Regulamento da Escola Normal Primária do distrito de Lisboa. Lisboa: Imprensa Nacional, 1861. (Coleção Oficial da Legislação Portuguesa, 1860). p. 814-821.

PORTUGAL. Regulamento da Escola Normal Primária para o sexo feminino no Distrito de Lisboa. Lisboa: Imprensa Nacional, 1864. (Coleção Oficial da Legislação Portuguesa, 1863). p. 532-538.

\section{PORTUGAL. Regulamento Geral do Ensino Primário} de 18 de junho de 1896. Lisboa: Imprensa Nacional, 1897. (Coleção Oficial da Legislação Portuguesa, 1896). p. 474-519.

PORTUGAL. Regulamento para a execução de leis sobre a instrução primária de 28 de julho de 1881. Lisboa: Imprensa Nacional, 1882. (Coleção Oficial da Legislação Portuguesa, 1881). p. 145-191.

PORTUGAL. Regulamento para o ensino primário de 20 de dezembro de 1850. Lisboa: Imprensa Nacional, 1851. (Coleção Oficial da Legislação Portuguesa, 1850). p. 896-903.

PROENÇA, Maria Cândida. A reforma Jaime Moniz. Lisboa: Colibri, 1997.

RODRIGUES, A. S. Os programas de matemática no ensino profissional. In: ALMEIDA, António José; MATOS, José Manoel (coord.). A matemática nos programas do ensino não-superior (1835-1974). Caparica: UIED/APM, 2014. p. 95-113.

Recebido em: 2/4/2019.

Aprovado em: 23/4/2019.

Publicado em: 8/11/2019. 
Endereço para correspondência:

José Manuel Matos

Universidade Federal de Juiz de Fora

Departamento de Matemática, Instituto de Ciências Exatas

Campus Universitário - Bairro Martelos

36036-900 Juiz de Fora, MG, Brasil

\section{Autores:}

José Manuel Matos

Doutor em Educação Matemática pela The University of Georgia.

Professor visitante da Universidade Federal de Juiz de Fora, Professor aposentado

da Universidade Nova de Lisboa. Licenciado em Física Matemática na Universidade

de Lisboa, Mestre em Educação pela Boston University.

Orcid: http://orcid.org/0000-0003-2809-6561

E-mail: jmm@fet.unl.pt

Alexandra Rodrigues

Doutora em Didática da Matemática pela Universidade da Beira Interior.

Mestre em Ensino da Matemática pela Universidade da Beira Interior. Licenciada

em Ensino da Matemática pela Faculdade de Ciências e Tecnologia da Universidade de Coimbra. Pertence ao Grupo de História e Memórias da Educação Matemática

da Associação de Professores de Matemática. Membro da UIED - Unidade de

Investigação Educação e Desenvolvimento da Universidade Nova de Lisboa.

Pesquisa em História da Educação Matemática e Ensino Profissional

Orcid: http://orcid.org/0000-0001-9022-4849

E-mail: alexsofiarod@gmail.com

\section{RUI CANDEIAS}

Mestre em Educação, na área de especialização em Didática da Matemática,

pela Faculdade de Ciências da Universidade de Lisboa. Licenciado em Ensino de

Matemática e Ciências da Natureza, pela Escola Superior de Educação Almeida

Garrett. Pertence ao Grupo de História e Memórias da Educacão Matemática

da Associação de Professores de Matemática. Membro da UIED - Unidade de

Investigação Educação e Desenvolvimento da Universidade Nova de Lisboa.

A área de investigação centra-se na história do ensino da Matemática nos

primeiros anos de escolaridade e no desenvolvimento curricular.

Orcid: http://orcid.org/0000-0002-4670-7090

E-mail: ruicandeias1@sapo.pt 